\title{
Mortality from stomach cancer in United States cement plant and quarry workers, 1950-80
}

\author{
H E AMANDUS
}

From the Division of Respiratory Disease Studies, National Institute for Occupational Safety and Health, Morgantown, West Virginia 26505, USA

ABSTRACT In 1978 a study of the mortality of United States cement plant and quarry workers was initiated. The vital status of a cohort of 5292 men who had been employed for at least five years in a cement plant between 1950 and 1980 was traced to 1 January 1980 . The mortality experience was evaluated for 4231 white men for whom complete work histories and demographic information were available. Deaths from stomach cancer were significantly increased during 1965-9 but not over the Nㅛ entire follow up period (1950-80). Additionally, stomach cancer mortality was not significantly $\circ$ associated with tenure under separate control for age at follow up, latency, nativity, or year of birth. Evidence from this and other epidemiological studies has not confirmed an association between the constituents of cement plant dust exposure and death from stomach cancer.

In 1978 studies of the environmental exposure, respiratory morbidity, and mortality of United States cement plant and quarry workers were begun by our laboratory ${ }^{1}$ (H Abrons et al, unpublished observations). The purpose of this paper is to evaluate the hypothesis that exposure to cement dust is associated with an increased risk of death from stomach cancer.

\section{Methods}

A sample of workers employed in 23 United States non-asbestos cement plants was selected for study. Plants were selected randomly by geographic region and were required to have operated before 1950 . Workers were included if employed at least five years in a cement plant some time between 1950 and 1960 .

The vital status of each worker was determined as at 1 January 1980 from information obtained from the United States Social Security Administration, Internal Revenue Service, postmasters, and inquiries of friends and relatives. Death certificates were collected and the underlying cause of death was coded according to the eighth revision of the International Classification of Diseases (adapted). ${ }^{2}$

A total of 8714 workers were enumerated from company records. Workers were excluded if they did not meet the inclusion criteria and these included 709 who had worked for under five years in a cement plant, 1791 who had left before 1950, and 94 who were hired after 1960. Additionally, 828 were excluded

Accepted 18 December 1985 because their work history records were not available $\vec{\oplus}$ before 1960. Many, however, of the 828 were hired $\%$ before 1940 and did not meet the inclusion criteria.

A final cohort of 5292 men met the inclusion criteria and vital status was determined for $5249(99 \cdot 2 \%)$. Death certificates were obtained for $1651(95 \cdot 7 \%)$ of the 1725 who had died. Complete work histories and $\frac{\otimes}{\square}$ data on date of birth, race, and sex were available for $4565(86.3 \%)$ of the 5292 men. Of the 4565 men, 4231 응 white men were selected for analysis in this paper; $565^{3}$ white men were excluded because of incomplete work histories or lack of information on date of birth.

A person-years analysis ${ }^{3}$ was used to evaluate the $\stackrel{\odot}{\Phi}$ mortality experience of the white male cohort from 13 January 1950 to 1 January 1980. Person-years of fol- $\frac{5}{3}$ low up were enumerated over five year age intervals, 10 year tenure intervals, 10 year latency intervals, and $\frac{0}{3}$ over five year follow up periods for time at risk from 1950 to 1980. Person-years were tallied from five years $ᄋ$ after date of hire or from 1 January 1950 (whichever $\frac{D}{O}$ occurred later), allowing for the period the cohort was free of mortality risk. Using this method the white N male cohort contributed 96429 person-years.

The expected number of deaths was computed ${ }_{0}$ using age-year specific death rates from the United $\omega$ States white male population. The standardised mortality ratio (SMR) was computed as the ratio of theo observed to the expected number of deaths multiplied $\Phi$ by $100 \%$. The observed number of deaths was $\stackrel{?}{+}$ assumed to be Poisson distributed, and a chi square $\frac{T}{\circ}$ test was used to test statistically whether the SMR differed from 100. 
Tenure was used as a surrogate estimate of exposure to cumulative cement plant dust. A possible association with cement plant exposure will be accepted if the stomach cancer mortality risk increases with tenure under control for age, race, sex, latency, and other stomach cancer risk factors. Tenure was defined as the number of years employed at a cement plant. Latency was defined as time from date of first employment in a cement plant to date of death or last date of follow up.

\section{Results}

MORTALITY FROM STOMACH CANCER BY TENURE, LATENCY, AND YEAR OF BIRTH

Mortality from stomach cancer was not significantly increased $(S M R=135)$ in the overall cohort or in any tenure group under control for latency (table 1). A gradient with tenure in stomach cancer mortality risk was not observed. SMRs for stomach cancer are presented in table 2 by year of follow up and year of birth. Mortality was not significantly increased for those born before or after 1900. The SMR was significantly increased during 1965-9 for the overall group and for those born before 1900. Deaths from stomach cancer had not significantly increased before 1965 or after 1969.

Owing to the small expected number of deaths $(<5)$ an accurate statistical test of the SMR could not be made for less than 20 years tenure under the control for latency (table 1) or for the 1965-9 period (table 2). The expected number of deaths, however, was 12.5 for greater than 20 years tenure and greater than
20 years latency (table 1) and the SMR (127) was not significantly greater than 100 .

MORTALITY FROM STOMACH CANCER BY TENURE UNDER CONTROL FOR NATIVITY

Nativity in a country where mortality rates for stomach cancer are high has been noted as a possible risk factor among migrants. The nativity of eight of the 16 cases born before 1900 was Europe or Mexico (countries with a higher stomach cancer mortality rate than the United States). The nativity of the 11 cases of stomach cancer born after 1900 was the United States.

To control for place of birth a case-control analysis was conducted. Cases with stomach cancer were matched with workers who died of causes other than stomach cancer or an accident. Matching criteria were age at hire within five years, latency within 10 years, cement plant, date of death within 10 years, and country of birth. Matching was successful for 25 of the 27 cases.

The results of the analysis did not suggest an association between death from stomach cancer and cement plant tenure (less than or greater than 20 years). The odds ratio for 16 case-control pairs born in the United States was 0.75 , and for all 25 pairs was $1 \cdot 3$. Neither odds ratio differed significantly from $1 \cdot 0$; however, the power of the statistical test was low to detect an odds ratio less than $2 \cdot 0$.

\section{Discussion}

The results of this study do not confirm that death from stomach cancer is associated with exposure to

Table 1 Observed $(O)$ and expected $(E)$ number of deaths from stomach cancer and $S M R^{*}$ by tenure and latency

\begin{tabular}{|c|c|c|c|c|c|c|c|c|c|}
\hline \multirow[t]{3}{*}{ Latency (years) } & \multicolumn{9}{|c|}{ Tenure (years) } \\
\hline & \multicolumn{3}{|c|}{$<20$} & \multicolumn{3}{|c|}{$>20$} & \multicolumn{3}{|c|}{ Total } \\
\hline & $O$ & $E$ & $S M R$ & $o$ & $\boldsymbol{E}$ & $S M R$ & $O$ & $\boldsymbol{E}$ & $S M R$ \\
\hline $\begin{array}{l}<20 \\
\geqslant 20 \\
\text { Total }\end{array}$ & $\begin{array}{r}5 \\
6 \\
11\end{array}$ & $\begin{array}{l}4.46 \\
3.03 \\
7.48\end{array}$ & $\begin{array}{l}112 \\
198 \\
198\end{array}$ & $\begin{array}{l}\overline{16} \\
16\end{array}$ & $\begin{array}{l}\overline{12.59} \\
12.59\end{array}$ & $\begin{array}{l}\overline{127} \\
127\end{array}$ & $\begin{array}{r}5 \\
22 \\
27\end{array}$ & $\begin{array}{r}4.46 \\
15.61 \\
20.07\end{array}$ & $\begin{array}{l}112 \\
141 \\
135\end{array}$ \\
\hline
\end{tabular}

*No SMR's differed significantly from 100 , p-value $<5 \%$.

Table 2 Observed $(O)$ and expected (E) number of deaths from stomach cancer and SMR by year of follow up and year of birth

\begin{tabular}{|c|c|c|c|c|c|c|c|c|c|c|c|c|}
\hline \multirow[t]{3}{*}{ Year of birth } & \multicolumn{12}{|c|}{ Year of follow up } \\
\hline & \multicolumn{3}{|c|}{$\leqslant 1964$} & \multicolumn{3}{|c|}{$1965-9$} & \multicolumn{3}{|c|}{$\geqslant 1970$} & \multicolumn{3}{|c|}{ Total } \\
\hline & $O$ & $E$ & $S M R$ & $O$ & $\boldsymbol{E}$ & $S M R$ & $o$ & $\boldsymbol{E}$ & $S M R$ & $O$ & $\boldsymbol{E}$ & $S M R$ \\
\hline $\begin{array}{l}<1900 \\
\geqslant 1900 \\
\text { Total }\end{array}$ & $\begin{array}{l}5 \\
1 \\
6\end{array}$ & $\begin{array}{l}6.55 \\
2.62 \\
9 \cdot 17\end{array}$ & $\begin{array}{l}76 \\
38 \\
65\end{array}$ & $\begin{array}{r}9 \\
4 \\
13\end{array}$ & $\begin{array}{l}1.83 \\
1.81 \\
3.64\end{array}$ & $\begin{array}{l}491^{*} \\
221 \\
357^{*}\end{array}$ & $\begin{array}{l}2 \\
6 \\
8\end{array}$ & $\begin{array}{l}2 \cdot 15 \\
5 \cdot 11 \\
7 \cdot 26\end{array}$ & $\begin{array}{r}93 \\
117 \\
110\end{array}$ & $\begin{array}{l}16 \\
11 \\
27\end{array}$ & $\begin{array}{r}10.53 \\
9.54 \\
20.07\end{array}$ & $\begin{array}{l}152 \\
115 \\
135\end{array}$ \\
\hline
\end{tabular}

*SMR differed significantly from 100 , $p$ value $<5 \%$. 
cement plant dust. Over the entire follow up period (1950-79), the mortality from stomach cancer was not significantly increased, and a gradient was not found with tenure under control for age, latency, year of birth, and nativity.

Two groups of workers were excluded from the white male cohort, the 828 men without a work history and the 565 white men with an incomplete work history or date of birth. Separate person-years analyses were conducted, and a significant increase in death from stomach cancer was not found in either group. Thus the negative results of this study are not likely to have been biased towards the null hypothesis by the exclusion of these groups from the white male cohort.

Although exposures in cement plants are perhaps involved, the increased mortality from stomach cancer during 1965-9 is more likely to be explained by other factors. Firstly, the lack of a gradient with tenure is not consistent with an exposure to an occupational carcinogen. Secondly, nativity or year of birth could explain some of the 1965-9 excess. Mortality from stomach cancer in 1965-9 was significantly increased in those born before 1900 but not among those born after 1900 . The nativity was Europe or Mexico for approximately $50 \%$ of the cases of stomach cancer born before 1900 , but all cases born after 1900 were born in the United States. Thirdly, the increased SMR in 1965-9 may be a chance occurrence as the expected number of deaths was low.

Fourthly, known gastric carcinogens have not been found in cement plants. Constituents of airborne cement plant dusts consist of trace metals, coal (for jobs in coal using areas), silica, and nuisance dusts. Abrons et al (unpublished observations) found traces of hexavalent chromium in a few samples of airborne dust collected in United States cement plants, but all the levels were below the recommended threshold limit value. Although exposure to coal dust has been associated with death from stomach cancer among cigarette smokers, ${ }^{45}$ it is an unlikely explanation for stomach cancer in cement workers because of the negligible exposure to coal dust in cement plants and quarries. With respect to quartz as a gastric carcinogen, epidemiological evidence weights against an association, ${ }^{610}$ but some positive evidence leads to speculation. ${ }^{11-13}$

McDowall studied 607 cement plant workers employed in 1939 in England and Wales. ${ }^{14}$ The mortality from stomach cancer was significantly increased in the overall cohort (SMR $=175)$ and was associated with an index of cement plant dust exposure. In addition, death from stomach cancer was significantly increased under control for social class. McDowall's results, however, did not confirm an association between cement plant exposure and gastric cancer.
Latency and tenure were not evaluated and a sur- $\frac{\vec{D}}{\mathrm{D}}$ rogate measure of cement plant dust exposure was? employed (job held in 1939) which may not represent $\overrightarrow{\vec{F}}$ a worker's cumulative or average respirable dust exposure. In any event the McDowall study raises the question of a possible association.

We cannot conclude from our results that there is $\frac{\rho}{\sigma}$ no association between exposure to cement plant dust $\varrho$ and death from stomach cancer because of the low $\%$ statistical power afforded by our cohort. Our results, $\vec{\circ}$ however, are not consistent with the hypothesis. Moreover, the results from other epidemiological $\vec{\omega}$ studies have not confirmed that constituents of $\stackrel{\circ}{\circ}$ cement plant and quarry dust are gastric carcinogens. Clearly, a conclusion about this hypothesis awaits a study with a sufficient number of cases with informa- $\omega$ tion on gastric cancer risk factors.

\section{References}

${ }^{1}$ Amandus HE, Ayersman J, Riffle D, Swecker S. The mortality of $\frac{\bar{c}}{}$ US portland cement plant workers, 1950-79. (Presented at the international conference on the health of miners, Pittsburg, $\mathrm{Pa}, \overrightarrow{\mathrm{O}}$ 1985.) Annals of the American Conference of Governmental Industrial Hygienists (in press).

${ }^{2}$ National Center for Health Statistics. International classification of diseases, adapted for use in the United States. 8th rev. US Department of Health Education and Welfare, Public Health Service, 1968. (PHS pub No 1693.)

${ }^{3}$ Monson RR. Analysis of relative survival and proportional $\frac{2}{(1)}$ mortality. Comput Biomed Res 1974;1:325-32.

4 Ames RG. Gastric cancer and coal mine dust exposure: a casecontrol study. Cancer 1983;52:1346-50.

${ }^{5}$ Wong W, Long R, Ames RG, Ong T. Role of nitrosation in the mutagenic activity of coal dust: a postutation for gastric carcinogenesis in coal miners. Environ Res 1983;32:298-304.

${ }^{6}$ Costello J. Mortality of metal miners: a retrospective cohort and case-control study. In: Wagner W, Rom W, Merchant J, eds. Health issues related to metal and nonmetallic miners. Boston: 3 Butterworth, 1983.

${ }^{7}$ McDonald JC, Gibbs W, Liddell FDK, McDonald AD. Mortality of the long exposure to cummingtonite-gruneite. Am Revi Respir Dis 1978;118:271-7.

${ }^{8}$ Armstrong BK, McNulty JC, Levitt LJ, Williams KA, Hobbs MST. Mortality in gold and coal miners in Western Australia 음 with special reference to lung cancer. Br J Ind Med 1979;36: 199-205.

9 Thomas TL. A preliminary investigation of mortality among work-을. ers in the pottery industry. Int $J$ Epidemiol 1982;11:175-80. $\mathrm{N}$

${ }^{10}$ Finkelstein M, Kusiak R, Suranyi G. Mortality among miners receiving workmen's compensation for silicosis in Ontario: $N$ 1940-75. J Occup Med 1982;24:663-7.

${ }^{11}$ Katsnelson BA, Mokronosova KA. Non-fibrous mineral dusts and $\omega$ malignant tumors, an epidemiological study of mortality. J Occup Med 1979;21:15-20.

12 Fox AJ, Goldblatt P, Kinlen LJ. A study of the mortality of Cornish tin miners. Br J Ind Med 1981;38:378-80.

13 Milham S. Occupational mortality in Washington State, 1950-79. US Department of Health and Human Services, 1983. (DHHS (NIOSH), Pub No 83-116.)

${ }^{14} \mathrm{McDowall} \mathrm{ME}$. A mortality study of cement workers. Br J Ind Med $\stackrel{\mathbb{D}}{\mathrm{Q}}$ 1984;41:179-82. 